\title{
BMJ Open Adverse events associated with endoscopic retrograde cholangiopancreatography: protocol for a systematic review and meta-analysis
}

\author{
Nauzer Forbes (D) , ${ }^{1,2}$ Grigorios I. Leontiadis, ${ }^{3,4}$ Marcus Vaska, ${ }^{5}$ \\ B. Joseph Elmunzer, ${ }^{6}$ Yuhong Yuan, ${ }^{4}$ Kirles Bishay, ${ }^{1,2}$ Zhao Wu Meng, ${ }^{1,2}$ \\ Jordan lannuzzi, ${ }^{1}$ Dylan E O'Sullivan, ${ }^{2,7}$ Brittany Mah, ${ }^{1,7}$ Arun C R Partridge (1) ,1 \\ Amanda M Henderson, ${ }^{1}$ Aatif Qureshi, ${ }^{1}$ Rajesh N Keswani, ${ }^{8}$ Sachin Wani, ${ }^{9}$ \\ Ronald J Bridges, ${ }^{1}$ Steven J Heitman, ${ }^{1,2}$ Robert J Hilsden (D) , ${ }^{1,2}$ Yibing Ruan (1) ,7,10 \\ Darren R Brenner (i) $2,7,10$
}

To cite: Forbes N, Leontiadis Gl, Vaska M, et al. Adverse events associated with endoscopic retrograde cholangiopancreatography: protocol for a systematic review and meta-analysis. BMJ Open 2021;11:e053302. doi:10.1136/ bmjopen-2021-053302

- Prepublication history and additional supplemental material for this paper are available online. To view these files, please visit the journal online (http://dx.doi.org/10.1136/ bmjopen-2021-053302).

Received 10 May 2021 Accepted 28 July 2021
Check for updates

(c) Author(s) (or their employer(s)) 2021. Re-use permitted under CC BY-NC. No commercial re-use. See rights and permissions. Published by BMJ.

For numbered affiliations see end of article.

Correspondence to

Dr Nauzer Forbes;

nauzer.forbes@ucalgary.ca

\section{ABSTRACT}

Introduction Endoscopic retrograde

cholangiopancreatography (ERCP) is performed to diagnose and manage conditions of the biliary and pancreatic ducts. Though effective, it is associated with common adverse events (AEs). The purpose of this study is to systematically review ERCP AE rates and report up-todate pooled estimates.

Methods and analysis A comprehensive electronic search will be conducted of relevant medical databases through 10 November 2020. A study team of eight data abstracters will independently determine study eligibility, assess quality and abstract data in parallel, with any two concordant entries constituting agreement and with discrepancies resolved by consensus. The primary outcome will be the pooled incidence of post-ERCP pancreatitis, with secondary outcomes including postERCP bleeding, cholangitis, perforation, cholecystitis, death and unplanned healthcare encounters. Secondary outcomes will also include rates of specific and overall AEs within clinically relevant subgroups determined a priori. DerSimonian and Laird random effects models will be used to perform meta-analyses of these outcomes. Sources of heterogeneity will be explored via meta-regression. Subgroup analyses based on median dates of data collection across studies will be performed to determine whether $\mathrm{AE}$ rates have changed over time.

Ethics and dissemination Ethics approval is not required for this study as it is a planned meta-analysis of previously published data. Participant consent is similarly not required. Dissemination is planned via presentation at relevant conferences in addition to publication in peerreviewed journals.

PROSPERO registration number

CRD42020220221.

\section{INTRODUCTION}

Endoscopic retrograde cholangiopancreatography (ERCP) is an essential and commonly performed advanced endoscopic procedure
Strengths and limitations of this study

- Our meta-analysis will provide to up-to-date estimates of procedural risks associated with the performance of endoscopic retrograde cholangiopancreatography.

- A comprehensive search strategy will be employed to capture all relevant studies and answer our study question.

- The strength of the body of evidence will be assessed using the Grading of Recommendations, Assessment, Development and Evaluation framework.

- A limitation of our approach is the likelihood of pooling outcome estimates using variable definitions of outcomes across studies, which we will partially mitigate by performing sensitivity analyses based on outcome definitions.

- Though the decision to exclude conference abstracts potentially disposes to publication bias, we feel that the unclear or ambiguous methodology often available from conference abstracts would add to potential study heterogeneity.

used in the diagnosis and treatment of several categories of biliary and pancreatic pathology. ${ }^{1-4}$ Although the role of standard ERCP has transitioned to that of a primarily therapeutic procedure, ERCP volumes have nevertheless risen over the past 10-15 years in the USA. ${ }^{6}$ ERCP is performed across high-volume and low-volume centres, and by endoscopists of variable experience and specialties. ${ }^{7}$ A steep learning curve during a specialised period of training results in an advanced skill set required to perform safe and effective ERCP. ${ }^{89}$

Although very effective overall, ${ }^{10}$ ERCP is widely known to have the highest adverse 
event (AE) profile among all commonly performed endoscopic procedures, with a collective AE rate of $>10 \%{ }^{11}$ Common AEs include post-ERCP pancreatitis (PEP), bleeding, infection, cholecystitis, perforation and cardiopulmonary events. ${ }^{11} 12$ PEP is the most common, with estimated rates of $5 \%-10 \%$ in all-comers, approaching or exceeding $20 \%$ in higher risk cases. ${ }^{11-13}$ Despite an emphasis on training and quality, both the incidence of PEP and its associated mortality are rising in the USA. ${ }^{14}$ Rates of post-ERCP bleeding range between $0.3 \%$ and $2 \% .^{15-17}$ Symptomatic post-ERCP infection (cholangitis with or without sepsis) is also a common $\mathrm{AE}$ following ERCP, with a reported range between $0.5 \%$ and $3 \%,{ }^{11}$ and is of particular interest in recent years given the rise of duodenoscope-related infections. ${ }^{18-21}$

ERCP AEs are commonly reported in studies of varying designs; however, few systematic reviews have synthesised available incidence rates of specific or overall AEs following ERCPs. A 2015 study synthesised the rates of PEP from randomised trials, ${ }^{13}$ but their search is now nearly 8 years out of date. Furthermore, other AE rates were not considered, and observational studies were not included. Observational studies are a required element of understanding true population rates of AEs, ${ }^{22} 23$ given that the patient mixes therein are more representative of the actual patient population in clinical practice compared with the highly selected participants in randomised trials. Given the frequency with which these events occur and their significant burden on the healthcare system, ${ }^{24}{ }^{25}$ it is crucial to obtain accurate, up-to-date data on which to base estimates of incidence. Furthermore, AE rates differ depending on clinically relevant patient-related and procedure-related parameters, but pooled estimates of incidences within these subgroups are largely unavailable. These estimates could be important so that patients and endoscopists are aware of specific risks associated with each procedure.

Prior meta-analyses on this topic have focused only on paediatric patients ${ }^{26}$ or instead on specific AEs or specific patient subgroups. ${ }^{132728}$ Therefore, we propose an up-todate, comprehensive and methodologically rigorous systematic review and meta-analysis to determine the incidence of AEs following ERCP in adult patients, both overall and within clinically relevant patient-related and procedure-related subgroups.

\section{METHODS}

\section{Overview and objectives}

Our meta-analysis will be conducted according to the Preferred Reporting Items for Systematic Reviews and Meta-Analyses and Meta-analysis Of Observational Studies in Epidemiology recommendations. ${ }^{29} 30$

The primary objective will be to determine the pooled overall incidence of PEP (the primary outcome) in adult patients undergoing ERCP. The secondary objectives will be to determine the pooled incidences of post-ERCP bleeding, cholangitis, perforation, cholecystitis, death and unplanned healthcare encounters, in addition to determining the rates of specific and overall AEs within clinically relevant subgroups determined a priori and described below.

\section{Eligibility criteria}

Given the comprehensive nature of the study question and outcomes of interest, two separate electronic searches will be conducted, with studies captured within either search being eligible for inclusion in the overall systematic review. The first search will focus on randomised trials only, while the second search will also include observational studies. For the first search, a study will be included in the final review if it meets all of the following criteria: (1) it presents original data in the form of a randomised clinical trial (with any primary research question), (2) the interventional arm or control arm represents adult patients receiving ERCP, (3) it makes reference to the determination of overall or specific ERCP-related AE(s) as a primary or secondary outcome; (4) it reports the incidence of at least one post-ERCP AE (including any of PEP, bleeding, symptomatic infection or cholangitis, perforation, cholecystitis, death or unplanned presentation to a healthcare facility within any follow-up period up to 30 days after the index procedure); (5) it is published in English and (6) at least $75 \%$ of study patients received their ERCP in the year 2000 or later. The year 2000 was chosen as a cut-off so that only studies representative of the current 'era' of ERCP are included. For the first search, a study will be excluded from the review if (1) it is a conference abstract or (2) if it reports data that overlaps with another study's patient population in part or in whole for the same outcome of interest. In the latter case, the study that includes the largest number of patients that had their ERCP conducted in the year 2000 or later will be included while any others are excluded.

For the second search, a study will be included in the final review if it meets all of the following criteria: (1) it is an observational study of any design; (2) its primary or secondary objective is to assess post-ERCP AE rates or outcomes in adults; (3) it reports the incidence of a specific post-ERCP AE, including any of the following: PEP, bleeding, symptomatic infection or cholangitis, perforation, cholecystitis, death or unplanned presentation to a healthcare facility within 30 days of the index procedure; (4) it is published in English and (5) at least $75 \%$ of study patients received their ERCP in the year 2000 or later. For the second search, a study will be excluded from the review if it meets any of the following criteria: (1) it is a case report; (2) it is a smaller study (fewer than 500 total study patients, with this threshold set to mitigate small study effects due to random error and to reduce the likelihood of including zero-event studies, which are problematic to meta-analyse); (3) it represents the experience of a single endoscopist; (4) it is a conference abstract or (5) it reports data that overlaps with another study's patient population in part or in whole for the same outcome. In the latter case, the study 


\begin{tabular}{|c|c|c|}
\hline & Inclusion criteria & Exclusion criteria \\
\hline $\begin{array}{l}\text { Search } \\
\text { aspect } 1\end{array}$ & $\begin{array}{l}\text { Original data } \\
\text { Randomised controlled } \\
\text { trial (with any research } \\
\text { question) } \\
\text { Interventional or control } \\
\text { arm of RCT represents } \\
\text { adult patients receiving } \\
\text { ERCP } \\
\text { An adverse event } \\
\text { is a primary and/or } \\
\text { secondary outcome }\end{array}$ & $\begin{array}{l}\text { Non-English } \\
\text { publication } \\
\text { Data overlaps } \\
\text { with data from } \\
\text { another study (in } \\
\text { part or in whole) } \\
\text { More than } \\
25 \% \text { of study } \\
\text { procedures } \\
\text { performed prior } \\
\text { to } 2000 \\
\text { Conference } \\
\text { abstract }\end{array}$ \\
\hline $\begin{array}{l}\text { Search } \\
\text { aspect } 2\end{array}$ & $\begin{array}{l}\text { Original data } \\
\text { Observational study } \\
\text { (prospective or } \\
\text { retrospective) } \\
\text { Reports on adult } \\
\text { patients receiving ERCP } \\
\text { Primary or secondary } \\
\text { objective of study is } \\
\text { determination of ERCP } \\
\text { adverse event(s) }\end{array}$ & $\begin{array}{l}\text { Small cohort of } \\
\text { patients (fewer } \\
\text { than 500) } \\
\text { Represents } \\
\text { the experience } \\
\text { of a single } \\
\text { endoscopist } \\
\text { Non-English } \\
\text { publication } \\
\text { Data overlaps } \\
\text { with data from } \\
\text { another study (in } \\
\text { part or in whole) } \\
\text { More than } \\
25 \% \text { of study } \\
\text { procedures } \\
\text { performed prior } \\
\text { to } 2000 \\
\text { Conference } \\
\text { abstract }\end{array}$ \\
\hline
\end{tabular}

ERCP, endoscopic retrograde cholangiopancreatography; RCT, randomised controlled trial.

that includes the largest number of patients that had their ERCP conducted in the year 2000 or later will be included while any others are excluded. Eligibility criteria for both aspects of the overall search strategy are summarised in table 1 .

\section{Search strategy and terms}

A comprehensive electronic search will be designed by a health research librarian and carried out in the electronic databases MEDLINE (Ovid), PubMed, CINAHL, EMBASE, Scopus, Web of Science and Evidence Based Medicine Reviews based on the eligibility criteria detailed above, from inception of each data source to the search date of 10 November 2020. English language citations from 2000 or later will be included. A combination of Medical Subject Heading and free-text terms will be used along with spelling variations and synonyms to create the two search strategies outlined above. A detailed list of search terms is provided in box 1, with a full search

\section{Box 1 Summary of electronic database search terms.*}

Search Aspect 1: Randomised controlled Trials

(ERCP OR "endoscopic retrograde cholangiopancreatography") $\rightarrow$ limit to RCTs

(ERCP OR "endoscopic retrograde cholangiopancreatography") AND ("adverse event**" OR "adverse effect*" OR "adverse reaction*" OR "post-ERCP pancreatitis" OR "post-endoscopic retrograde cholangiopancreatography pancreatitis" OR pancreatitis OR hemorrhagehaemorrhage $\mathrm{OR}$ haemorrhage $\mathrm{OR}$ cholangitis $\mathrm{OR}$ bleeding $\mathrm{OR}$ infection* $O R$ cholecystitis $O R$ perforation $O R$ cardiopulmonary $O R$ sepsis $O R$ complication* OR unplanned OR event* OR sedation OR cholecystectomy OR choledocholithiasis $\mathrm{OR}$ "risk factor*" OR "postoperative complication*" OR "treatment outcome*" OR inflammation OR rupture) $\rightarrow$ limit to RCTs Search Aspect 2: Observational Studies

(ERCP OR "endoscopic retrograde cholangiopancreatography") $\rightarrow$ limit to cohort/observational studies

(ERCP OR "endoscopic retrograde cholangiopancreatography") AND ("adverse event**" OR "adverse effect*" OR "adverse reaction*" OR "post-ERCP pancreatitis" OR "post-endoscopic retrograde cholangiopancreatography pancreatitis" OR pancreatitis OR hemorrhagehaemorrhage OR haemorrhage OR cholangitis OR bleeding OR infection* OR cholecystitis OR perforation OR cardiopulmonary OR sepsis OR complication* OR unplanned OR event* OR sedation OR cholecystectomy OR choledocholithiasis OR "risk factor*" OR "postoperative complication*" OR "treatment outcome*" OR inflammation OR rupture) $\rightarrow$ limit to cohort/observational studies

*Full electronic search strategy provided in online supplemental materials.

planning document provided in the online supplemental materials.

\section{Study selection and data abstraction}

All citations will be imported into DistillerSR (Evidence Partners, Ottawa, Canada) and any duplicate entries will be removed. Given the large volume of anticipated citations identified in the initial searches, eight reviewers (KB, ZWM, JI, DEO, BM, ACRP, AMH and AQ) will be randomly assigned roughly equal numbers of citations. Assessments by the first two reviewers will be used for titles and abstracts to identify citations for potential fulltext review. A vote of 'both include' or 'both exclude' by any two of the eight reviewers will be considered definitive. Discrepancies will be resolved by consensus of an a priori committee of study investigators (NF, YR and DB). All included citations will then undergo independent duplicate full-text abstraction by two reviewers (of the same pool of eight), with discrepancies again being resolved by consensus. Data will then be extracted into standardised abstraction forms in duplicate, with separate forms for each aspect of the search strategy. Forms will include authors, year of publication, study design and country(ies) in which the research was carried out, study setting, recruitment period, sample sizes, patient sex, age, and comorbidity, procedural indication(s), relevant preprocedural parameters (including imaging studies and bilirubin levels) description of intervention(s), rates of AEs (in absolute numbers and proportions), outcome definitions and follow-up periods. Where possible, 


\begin{tabular}{|c|c|}
\hline Category & Subgroups \\
\hline $\begin{array}{l}\text { Patient } \\
\text { demographics and } \\
\text { characteristics }\end{array}$ & $\begin{array}{l}\text { Female vs male sex } \\
\text { Age }<50 \text { versus } \geq 50 \\
\text { Inpatient vs outpatient status } \\
\text { Degree of comorbidity (Charlson } \\
\text { Comorbidity Index or other, TBD) } \\
\text { Underlying primary sclerosing } \\
\text { cholangitis } \\
\text { Liver transplant status } \\
\text { Presence of antiplatelet or } \\
\text { anticoagulant medications } \\
\text { Presence vs absence of PEP } \\
\text { prophylaxis }\end{array}$ \\
\hline Practice settings & $\begin{array}{l}\text { Academic institutions vs community } \\
\text { practices } \\
\text { Low-volume vs high-volume centres } \\
\text { and/or endoscopists (cut-off points } \\
\text { TBD) }\end{array}$ \\
\hline $\begin{array}{l}\text { Procedural } \\
\text { indications }\end{array}$ & $\begin{array}{l}\text { Pancreatic vs biliary indications } \\
\text { Choledocholithiasis (suspected or } \\
\text { confirmed) } \\
\text { Malignant obstruction } \\
\text { Benign obstruction }\end{array}$ \\
\hline $\begin{array}{l}\text { Intraprocedural } \\
\text { techniques }\end{array}$ & $\begin{aligned} & \text { Sphincterotomy } \\
& \text { Sphincteroplasty } \\
& \text { Precut sphincterotomy } \\
& \text { Needle knife papillotomy } \\
& \text { Biliary stent placement } \\
& \text { - Mechanical lithotripsy } \\
& \text { Cholangioscopy and/or } \\
& \text { pancreatoscopy } \\
& \text { Pancreatic vs common bile duct } \\
& \text { cannulation }\end{aligned}$ \\
\hline $\begin{array}{l}\text { Study } \\
\text { methodology }\end{array}$ & $\begin{array}{l}\text { North American vs European vs } \\
\text { Asian-Pacific } \\
\text { Study publication date } \\
\text { Median data collection date (2000- } \\
\text { 2009, 2010-2014, 2015-present) } \\
\text { Study design (retrospective vs } \\
\text { prospective observational vs } \\
\text { randomised controlled trial) } \\
\text { ASGE Lexicon vs non-Lexicon } \\
\text { definition(s) of outcomes }\end{array}$ \\
\hline
\end{tabular}

ASGE, American Society for Gastrointestinal Endoscopy; PEP, post-ERCP pancreatitis; TBD, to be determined.

the severity of AEs will also be captured, including as an example mild, moderate and severe pancreatitis according to the Atlanta classification, ${ }^{31}$ so that pooled data can also be reported according to severity. Data will be abstracted both on the patient level as well as the procedure level, as available. Relevant subgroups (table 2) will also be abstracted.

\section{Outcome definitions}

A challenge with pooling rates of ERCP AEs is that nonuniversal definitions of outcomes are employed across studies. Detailed study-specific outcome definitions will be abstracted to help address this issue. Outcome definitions will be compared against those described in the American Society for Gastrointestinal Endoscopy (ASGE) Lexicon $^{32}$ and the European Society for Gastrointestinal Endoscopy Guideline. ${ }^{33}$ Studies not reporting clear outcomes definitions or those employing non-guideline/ Lexicon definitions will be flagged for sensitivity analyses. Study-specific mechanisms of outcome capture will also be abstracted so that these can be considered separately. ${ }^{34}$ For the primary outcome (PEP), the ASGE Lexicon definition requires typical pain with amylase or lipase $>3$ times the upper limit of normal. ${ }^{32}$

\section{Risk of bias}

Two authors will independently conduct risk of bias assessments for all included studies. Assessment of included randomised studies will be performed using the Cochrane Risk of Bias tool, V.2 (RoB 2) ${ }^{34}$ while the quality of observational studies will be assessed using the ROBINS-I tool. ${ }^{35}$ Discrepancies will be resolved by consensus.

\section{Statistical analysis, subgroup and sensitivity analyses}

We will perform DerSimonian and Laird random effects meta-analyses to report the pooled incidence rates of individual post-ERCP AEs along with 95\% CIs. Study weights will be measured using the inverse variance method. Incidence rates from observational studies and randomised trials will be pooled separately (at no point being combined). Heterogeneity between studies will be assessed with the $\mathrm{I}^{2}$ and $\chi^{2}$ statistics. We will consider $\mathrm{p}$ values of $<0.10$ for the $\chi^{2}$ statistic or an $\mathrm{I}^{2}$ value $>50 \%$ to indicate substantial heterogeneity, which will be further investigated with subgroup analyses. Subgroup analyses will be performed using relevant study-related, procedurerelated and patient-related characteristics selected a priori. These are summarised in table 2. In addition, sources of heterogeneity will also be tested by performing meta-regression on these a priori selected characteristics. We will examine the $\mathrm{I}^{2}$ and adjusted $\mathrm{R}^{2}$ statistics to estimate the fraction of heterogeneity accounted for by these characteristics.

To determine whether $\mathrm{AE}$ rates have changed over time, we will perform subgroup analyses based on the median dates of data collection in individual studies for each type of AE. Median data collection will be assigned a single value per study and studies will be separated into three periods: (a) 2000-2009, (b) 2010-2014 and (c) 2015-present. Meta-regression will be performed to determine whether there are any significant differences in specific or overall AE rates between periods. Periods were chosen based on the 2012 publication of the seminal manuscript on rectal non-steroidal anti-inflammatory agents to prevent $\mathrm{PEP}^{36}$ and a 3-year lag period between study dissemination and clinical practice adoption.

We will also conduct a series of sensitivity analyses whereby studies of varying quality as per ROBINS-I and RoB 2 are considered separately and whereby studies 
employing non-ASGE-Lexicon AE definitions will be considered separately. Inter-study heterogeneity will be assessed using the Cochrane $\mathrm{I}^{2}$ statistic. Publication bias will be assessed by visual inspection of funnel plots in addition to performing Egger's and Begg's tests. ${ }^{37} 38$ The statistical packages Revman 5.1 (Cochrane Collaboration) and Stata 14.0 (StataCorp) will be used for all analyses. The strength of the body of evidence will then be assessed using the Grading of Recommendations, Assessment, Development and Evaluation framework. ${ }^{39}$

\section{Patient and public involvement}

No patients or public were involved in study design.

\section{ETHICS AND DISSEMINATION}

Ethics approval is not required for this study as it is a planned meta-analysis of the previously published data. Participant consent is similarly not required. Dissemination is planned via presentation at relevant conferences in addition to publication in peer-reviewed journals.

\section{DISCUSSION}

This systematic review and meta-analysis will provide up-to-date estimates of incidences of the most common AEs associated with the performance of ERCP. Though ERCP in 2020 is primarily a therapeutic procedure, with minimal diagnostic indications, it remains one of the most commonly performed endoscopic procedures in the USA and world-wide, with volumes having increased over time.${ }^{56}$ Even though ERCP is a relatively safe procedure overall, AEs are more prevalent with its performance than any other endoscopic procedure. Thus, it behoves endoscopists performing ERCP to be acutely aware of the most precise and up-to-date estimates of risk possible. If possible, patient-specific and procedure-specific estimates of risk should also be ascertained, which is also a goal of the proposed study. Obtaining these estimates could help set up appropriate patient expectations of risk and could also serve to optimise the peri-procedural management of patients undergoing ERCP.

Specific knowledge gaps are particularly important to bridge regarding ERCP AEs. In particular, accurate estimates of the rate of post-ERCP symptomatic infections (cholangitis or sepsis) are particularly important given the growing concerns around duodenoscope-related infections. ${ }^{18-21}$ Obtaining accurate estimates of the overall burden of post-ERCP infection is the first step toward describing the relatively smaller infection risk attributable directly to duodenoscope contamination and transmission. Similarly, estimates of postsphincterotomy and/ or post-sphincteroplasty bleeding are variable, ${ }^{15-17}$ and no pooled estimates to date are available. With regards to rarer AEs such as cholecystitis and perforation, evidence is even more scarce. Thus, an urgent but unmet need is present to accurately define the overall and specific $\mathrm{AE}$ profile associated with ERCP.
Though this protocol was designed to limit sources of bias through rigorous methodology, there are nevertheless potential limitations that require acknowledgement. As with any meta-analysis, the certainty of pooled estimates is limited by the quality of input studies. With this topic in particular, it is anticipated that study cohorts will be described using variable levels of detail regarding demographics, comorbidities, procedural indications and procedural interventions. To mitigate this, we divided our study into two main analyses; the first, inclusive of randomised controlled trials, is expected to be more granular in terms of these details and is thus expected to yield more robust patient-specific and procedure-specific estimates of risk. The second, inclusive of only large observational studies, is expected to yield more pragmatic 'real-world' estimates of risk. For this analysis, a preset cut-off point of 500 patients was chosen to mitigate smallstudy effects. The 'delta', or gap between these two types of estimates, will also be a crucial aspect of our findings that we plan on discussing as it relates to implications on evidence interpretation and on clinical practice.

Another limitation of our approach is the possibility of pooling outcome estimates using variable definitions of outcomes across studies. To mitigate this, we will abstract study-specific outcome definitions and perform sensitivity analyses whereby studies with unclear or absent definitions are separately analysed. Even with this approach, we expect there to be some degree of (acceptable) variability between study definitions, but we will compare study-specific definitions against the ASGE Lexicon's $\mathrm{AE}$ definitions ${ }^{32}$ to ensure that we only pool studies adhering to minimal thresholds for attribution of AEs. For instance, for post-ERCP bleeding, we will ensure that at minimum, studies require a haemoglobin drop of $>2 \mathrm{~g}$ as part of their definition, to prevent inclusion of patients with intraprocedural or non-clinically significant postprocedural bleeding, which has been demonstrated to be of limited consequence. ${ }^{12}$ Another limitation includes missing studies due to our decision to restrict our inclusions to English studies with the majority of data collected after the year 2000. Although this is a valid concern, we felt it was more important to capture evidence most representative of current practices, techniques and technologies. Therefore, studies with a significant volume of study procedures performed prior to the year 2000 were deemed to be at risk of not representing current ERCP practice. Finally, we have made the decision to exclude conference abstracts from our study. Though this potentially disposes to publication bias, we feel that the unclear or ambiguous methodology often available from conference abstracts would add to potential study heterogeneity.

Overall, despite these limitations, we anticipate that our study will bridge important knowledge gaps pertaining to ERCP-associated AEs. Our results could potentially improve patient care and satisfaction by providing more detailed and up-to-date estimates of ERCP-related risk. Accurate $\mathrm{AE}$ estimates will also facilitate the design of future prospective ERCP studies including randomised 
trials and could potentially have meaningful implications on training and practice standards.

\section{Author affiliations}

${ }^{1}$ Department of Medicine, Division of Gastroenterology and Hepatology, University of Calgary, Calgary, Alberta, Canada

${ }^{2}$ Department of Community Health Sciences, University of Calgary, Calgary, Alberta, Canada

${ }^{3}$ Department of Medicine, Division of Gastroenterology, McMaster University, Hamilton, Ontario, Canada

${ }^{4}$ Farncombe Family Digestive Health Research Institute, McMaster University, Hamilton, Ontario, Canada

${ }^{5}$ Knowledge Resource Service, Alberta Health Services, Calgary, Alberta, Canada ${ }^{6}$ Division of Gastroenterology and Hepatology, Medical University of South Carolina, Charleston, South Carolina, USA

${ }^{7}$ Department of Oncology, Cumming School of Medicine, University of Calgary, Calgary, Alberta, Canada

${ }^{8}$ Division of Gastroenterology, Feinberg School of Medicine, Northwestern University, Chicago, Illinois, USA

${ }^{9}$ Division of Gastroenterology and Hepatology, University of Colorado Anschutz Medical Campus, Aurora, Colorado, USA

${ }^{10}$ Department of Cancer Epidemiology and Prevention Research, Cancer Control Alberta, Alberta Health Services, Calgary, Alberta, Canada

Contributors NFand GIL: Conception and design. NF, GIL, MV, YY, DEOS, BJE and DB: analysis plan. NF: drafting of the article. NF, GIL, MV, BJE, YY, KB, ZWM, JI, DEOS, BM, ACRP, AMH, AQ, RNK, SW, RJB, SJH, RJH, YR and DB:critical revision of the article for important intellectual content. NF, GIL, MV, BJE, YY, KB, ZWM, Jl, DEOS, BM, ACRP, AMH, AQ, RNK, SW, RJB, SJH, RJH, YR and DB: final approval of the article.

Funding This study was funded by the N.B. Hershfield Chair in Therapeutic Endoscopy, University of Calgary.

Competing interests None declared.

Patient consent for publication Not required.

Provenance and peer review Not commissioned; externally peer reviewed.

Supplemental material This content has been supplied by the author(s). It has not been vetted by BMJ Publishing Group Limited (BMJ) and may not have been peer-reviewed. Any opinions or recommendations discussed are solely those of the author(s) and are not endorsed by BMJ. BMJ disclaims all liability and responsibility arising from any reliance placed on the content. Where the content includes any translated material, BMJ does not warrant the accuracy and reliability of the translations (including but not limited to local regulations, clinical guidelines, terminology, drug names and drug dosages), and is not responsible for any error and/or omissions arising from translation and adaptation or otherwise.

Open access This is an open access article distributed in accordance with the Creative Commons Attribution Non Commercial (CC BY-NC 4.0) license, which permits others to distribute, remix, adapt, build upon this work non-commercially, and license their derivative works on different terms, provided the original work is properly cited, appropriate credit is given, any changes made indicated, and the use is non-commercial. See: http://creativecommons.org/licenses/by-nc/4.0/.

\section{ORCID iDs}

Nauzer Forbes http://orcid.org/0000-0002-6966-3908

Arun C R Partridge http://orcid.org/0000-0002-4191-0970

Robert J Hilsden http://orcid.org/0000-0003-1545-1093

Yibing Ruan http://orcid.org/0000-0002-2417-7172

Darren R Brenner http://orcid.org/0000-0002-3027-290X

\section{REFERENCES}

1 Maple JT, Ikenberry SO, et al, ASGE Standards of Practice Committee. The role of endoscopy in the management of choledocholithiasis. Gastrointest Endosc 2011;74:731-44.

2 Adler DG, Baron TH, Davila RE, et al. ASGE guideline: the role of ERCP in diseases of the biliary tract and the pancreas. Gastrointest Endosc 2005;62:1-8.

3 Anderson MA, Appalaneni V, et al, American Society for Gastrointestinal Endoscopy (ASGE) Standards of Practice
Committee. The role of endoscopy in the evaluation and treatment of patients with biliary neoplasia. Gastrointest Endosc 2013;77:167-74.

4 Chandrasekhara V, Chathadi KV, et al, ASGE Standards of Practice Committee. The role of endoscopy in benign pancreatic disease. Gastrointest Endosc 2015;82:203-14.

5 Kröner PT, Bilal M, Samuel R, et al. Use of ERCP in the United States over the past decade. Endosc Int Open 2020;8:E761.

6 Ahmed M, Kanotra R, Savani GT, et al. Utilization trends in inpatient endoscopic retrograde cholangiopancreatography (ERCP): a crosssectional us experience. Endosc Int Open 2017;5:E261-71.

7 Testoni PA, Mariani A, Giussani A, et al. Risk factors for post-ERCP pancreatitis in high- and low-volume centers and among expert and non-expert operators: a prospective multicenter study. $\mathrm{Am} \mathrm{J}$ Gastroenterol 2010;105:1753-61.

8 Wani S, Keswani RN, Han S, et al. Competence in Endoscopic Ultrasound and Endoscopic Retrograde Cholangiopancreatography, From Training Through Independent Practice. Gastroenterology 2018;155:1483-94.

9 Wani S, Han S, Simon V, et al. Setting minimum standards for training in EUS and ERCP: results from a prospective multicenter study evaluating learning curves and competence among advanced endoscopy trainees. Gastrointest Endosc 2019;89:1160-8.

10 Mariani A, Segato S, Anderloni A, et al. Prospective evaluation of ERCP performance in an Italian regional database study. Dig Liver Dis 2019;51:978-84.

11 , Chandrasekhara V, Khashab MA, et al, ASGE Standards of Practice Committee. Adverse events associated with ERCP. Gastrointest Endosc 2017:85:32-47.

12 Rustagi T, Jamidar PA. Endoscopic retrograde cholangiopancreatography-related adverse events: general overview. Gastrointest Endosc Clin N Am 2015;25:97-106.

13 Kochar B, Akshintala VS, Afghani E, et al. Incidence, severity, and mortality of post-ERCP pancreatitis: a systematic review by using randomized, controlled trials. Gastrointest Endosc 2015;81:143-9.

14 Mutneja H, Vohra I, Go A. Temporal trends and mortality of PostEndoscopic retrograde cholangiopancreatography pancreatitis in the United States: a nationwide analysis. Endoscopy 2020.

15 Cotton PB, Garrow DA, Gallagher J, et al. Risk factors for complications after ERCP: a multivariate analysis of 11,497 procedures over 12 years. Gastrointest Endosc 2009;70:80-8.

16 Christensen M, Matzen P, Schulze S, et al. Complications of ERCP: a prospective study. Gastrointest Endosc 2004;60:721-31.

17 Freeman ML, Nelson DB, Sherman S, et al. Complications of endoscopic biliary sphincterotomy. N Engl J Med 1996;335:909-19.

18 Preventable tragedies: Superbugs and how ineffective monitoring of medical device safety fails patients in: U. S. Senate Health E, Labor, and Pensions Committee, ed 2016.

19 Muscarella LF. Risk of transmission of carbapenem-resistant Enterobacteriaceae and related "superbugs" during gastrointestinal endoscopy. World J Gastrointest Endosc 2014;6:457-74.

20 Forbes N, Heitman S, McCulloch P. Infection control in ERCP: a human factors perspective. Clin Transl Gastroenterol 2020;11:e00214.

21 Humphries RM, McDonnell G. Superbugs on Duodenoscopes: the challenge of cleaning and disinfection of reusable devices. J Clin Microbiol 2015;53:3118-25.

22 Page MJ, McKenzie JE, Kirkham J, et al. Bias due to selective inclusion and reporting of outcomes and analyses in systematic reviews of randomised trials of healthcare interventions. Cochrane Database Syst Rev 2014:Mr000035.

23 Golder S, Loke YK, Bland M. Meta-Analyses of adverse effects data derived from randomised controlled trials as compared to observational studies: methodological overview. PLOS Med 2011;8:e1001026.

24 Fagenholz PJ, Fernández-del Castillo C, Harris NS, et al. Direct medical costs of acute pancreatitis hospitalizations in the United States. Pancreas 2007:35:302-7.

25 Inamdar S, Sejpal DV, Ullah M, et al. Weekend vs. weekday admissions for cholangitis requiring an ERCP: comparison of outcomes in a national cohort. Am J Gastroenterol 2016;111:405-10.

26 Usatin D, Fernandes M, Allen IE, et al. Complications of endoscopic retrograde cholangiopancreatography in pediatric patients; a systematic literature review and meta-analysis. $J$ Pediatr 2016;179:160-5.

27 Mashiana HS, Dhaliwal AS, Sayles H, et al. Endoscopic retrograde cholangiopancreatography in cirrhosis - a systematic review and meta-analysis focused on adverse events. World J Gastrointest Endosc 2018:10:354-66.

28 Iqbal U, Anwar H, Khan MA, et al. Safety and efficacy of endoscopic retrograde cholangiopancreatography in nonagenarians: a systematic review and meta-analysis. Dig Dis Sci 2021;56. 
29 Moher D, Shamseer L, Clarke M, et al. Preferred reporting items for systematic review and meta-analysis protocols (PRISMA-P) 2015 statement. Syst Rev 2015;4:1.

30 Stroup DF, Berlin JA, Morton SC, et al. Meta-Analysis of observational studies in epidemiology: a proposal for reporting. meta-analysis of observational studies in epidemiology (MOOSE) group. JAMA 2000;283:2008-12.

31 Banks PA, Bollen TL, Dervenis C, et al. Classification of acute pancreatitis--2012: revision of the Atlanta classification and definitions by international consensus. Gut 2013;62:102-11.

32 Cotton PB, Eisen GM, Aabakken L, et al. A lexicon for endoscopic adverse events: report of an ASGE workshop. Gastrointest Endosc 2010;71:446-54.

33 Dumonceau J-M, Kapral C, Aabakken L, et al. ERCP-related adverse events: European Society of gastrointestinal endoscopy (ESGE) guideline. Endoscopy 2020;52:127-49.
34 Higgins J, Green S. Cochrane Handbook for systematic reviews of interventions, 2011.

35 Sterne JA, Hernán MA, Reeves BC, et al. ROBINS-I: a tool for assessing risk of bias in non-randomised studies of interventions. BMJ 2016;355:i4919.

36 Elmunzer BJ, Scheiman JM, Lehman GA, et al. A randomized tria of rectal indomethacin to prevent post-ERCP pancreatitis. $N$ Engl $J$ Med 2012;366:1414-22.

37 Egger M, Davey Smith G, Schneider M, et al. Bias in meta-analysis detected by a simple, graphical test. BMJ 1997:315:629-34.

38 Begg CB, Mazumdar M. Operating characteristics of a rank correlation test for publication bias. Biometrics 1994:50:1088-101.

39 Guyatt GH, Oxman AD, Vist GE, et al. GRADE: an emerging consensus on rating quality of evidence and strength of recommendations. BMJ 2008;336:924-6. 